\title{
ВMJ Global Health Delivering integrated care after sexual violence in the Democratic Republic of the Congo
}

\author{
Joshua Bress, ${ }^{1}$ Givano Kashemwa, ${ }^{1}$ Christine Amisi, ${ }^{2}$ Jean Armas, ${ }^{\oplus 1}$ \\ Cindy McWhorter, ${ }^{1}$ Theodore Ruel, ${ }^{3}$ Arthur J Ammann, ${ }^{1}$ Denis Mukwege, ${ }^{2}$ \\ Lisa M Butler ${ }^{4}$
}

\begin{abstract}
To cite: Bress J, Kashemwa G, Amisi C, et al. Delivering integrated care after sexual violence in the Democratic Republic of the Congo. BMJ Glob Health 2019;4:e001120. doi:10.1136/ bmjgh-2018-001120
\end{abstract}

Handling editor Seye Abimbola GK, CA, JA, CM, TR, AJA, DM and LMB contributed equally.

Received 15 August 2018 Revised 16 January 2019 Accepted 2 February 2019

\section{Check for updates}

(c) Author(s) (or their employer(s)) 2019. Re-use permitted under CC BY-NC. No commercial re-use. See rights and permissions. Published by BMJ.

${ }^{1}$ Global Strategies, Albany, California, USA

${ }^{2}$ Department of Obstetrics and Gynecology, Panzi Hospital, Bukavu, The Democratic Republic of the Congo ${ }^{3}$ Department of Pediatrics, Division of Pediatric Infectious Diseases and Global Health, University of California San Francisco, San Francisco, California, USA

${ }^{4}$ Institute for Collaboration on Health, Intervention and Policy, University of Connecticut, Storrs, Connecticut, USA

Correspondence to

Dr Joshua Bress:

josh.bress@globalstrategies.org

\section{ABSTRACT}

In the eastern Democratic Republic of the Congo, ongoing armed conflict increases the incidence of gender-based violence (GBV) and presents a distinct and major barrier to care delivery for all survivors of GBV. A specific challenge is providing emergency contraception, HIV prophylaxis and treatment for sexually transmitted infections to all survivors within 72 hours of violence. To address the multiple barriers to providing this time-sensitive medical care, Global Strategies and Panzi Hospital implemented the Prevention Pack Program. The Prevention Pack is a prepackaged post-rape medical kit containing antiretroviral post-exposure prophylaxis, antibiotics for treatment of sexually transmitted infections and emergency contraception. The Prevention Pack Program combines community sensitisation about post-rape medical care with the provision of Prevention Packs and the implementation of a cloud-based and Global Positioning System (GPS)-enabled inventory management system. The Panzi Hospital gender-based violence team implemented the Prevention Pack Program at Panzi Hospital and 12 rural clinics in the South Kivu Province. The data manager took GPS coordinates of each site, provided an initial stock of Prevention Packs and then called all sites daily to determine demand for post-rape care and Prevention Pack consumption. Inventory data were entered into the GPS-enabled cloud-based inventory management system. Project personnel used the consumption rate, trends and geolocation of sites to guide Prevention Pack restocking strategy. Between 2013 and 2017, a total of 8206 individuals presented for care following rape at the study sites. Of the 1414 individuals who presented in the rural areas, 1211 (85.6\%) did so within the first 72 hours of reported rape. Care was delivered continuously and without a single stockout of medication across all sites. The Prevention Pack Program provided timely and consistent access to emergency contraception, HIV prophylaxis and treatment for sexually transmitted infections for rape survivors in the eastern Democratic Republic of the Congo.

\section{INTRODUCTION}

Gender-based violence (GBV) is a worldwide problem, with women in resource-limited and
Summary box

In the eastern Democratic Republic of the Congo (DRC), ongoing armed conflict increases the incidence of gender-based violence and also presents a distinct and major barrier to care delivery for all survivors of sexual violence.

- To overcome the barriers to providing a constant inventory of post-rape care medications to survivors of sexual violence within 72 hours, Global Strategies and Panzi Hospital implemented the Prevention Pack Program. The Prevention Pack Program combines community sensitisation, provision of a pre-packaged post-rape medical kit, and a cloud-based and GPS-enabled inventory management system.

- Between 2013 and 2017, we provided 2081 postrape medical kits to survivors of sexual violence at 13 sites in the South Kivu Province of the DRC. This care was delivered continuously and without a single stockout in an unstable and remote area.

- The Prevention Pack Program can improve delivery of immediate post-rape medical care in remote conflict settings by addressing inventory challenges and creating a map of demand for post-rape care across wide geographies.

conflict settings suffering a disproportionate burden. ${ }^{1}$ In the Democratic Republic of the Congo (DRC), Peterman et al concluded that an estimated 400000 women are raped annually and that over 3000000 women experience intimate partner violence. ${ }^{2}$ Additionally, the Democratic Republic of the Congo Demographic and Health Survey 2013-2014 reported that $16 \%$ of respondents had experienced sexual violence in the last 12 months. ${ }^{3}$ While media attention has focused on mass violence committed by soldiers and paramilitary personnel, data suggest that sexual violence in DRC is not limited to armed and unknown perpetrators. ${ }^{2}$ In the Kivu Provinces of eastern DRC, ongoing armed conflict, though not accounting for all cases of sexual 
violence, nonetheless presents a distinct and major barrier to care delivery for all rape victims. ${ }^{45}$

The complications of sexual violence include HIV infection, sexually transmitted infections (STIs), unwanted pregnancy, gynaecological injuries, stigmatisation and long-term psychological difficulties. ${ }^{67}$ In the DRC, there is an estimated HIV prevalence of $0.7 \%{ }^{8}$ The standard of care for rape survivors is to provide emergency contraception, STI treatment and to strongly consider HIV post-exposure prophylaxis. ${ }^{9}$ While such care is possible in specialised centres, individual and system-level barriers limit the implementation of these recommendations in resource-limited settings, especially rural and unstable areas. ${ }^{10}$ Complex dosing schemes, the management of side effects and the requirement that treatment be tailored based on an individualised assessment of HIV risk impede post-rape care in rural settings where general practitioners are overwhelmed providing primary care and see too few rape survivors individually to gain comfort with the care protocol. ${ }^{11}{ }^{12}$ On a system level, it is challenging to maintain stock at multiple small clinics given volatile consumption of medications and limited medication shelf-lives. ${ }^{13}$ While multiple articles have characterised the high prevalence of GBV during conflict while highlighting the need for additional implementation research, ${ }^{13613-15}$ few data exist on the optimal strategy to deliver time-sensitive post-rape medical care in these locations.

In 2013, Global Strategies, an American non-governmental organisation, partnered with Panzi Hospital, a leading Congolese medical centre located in the provincial capital of Bukavu, to identify and address barriers to delivering emergency contraception, HIV prophylaxis and STI treatment following sexual violence in the rural areas of the South Kivu Province. Data from a needs assessment conducted by Global Strategies and Panzi Hospital in 2009-2010 identified the following barriers: (1) women were unaware that the therapy existed, (2) treatment was not available within 72 hours on foot, (3) clinics had near-constant medication stockouts, (4) rural practitioners could not properly assemble and administer the drug regimen, and (5) the regimens that were available contained poorly tolerated five-drug combinations. To overcome the barriers limiting the consistent provision of post-rape medical care in remote and resource-limited settings, we created the Prevention Pack Program.

\section{Setting}

The programme was implemented in the South Kivu Province in eastern DRC at Panzi Hospital and a subset of 12 rural clinics that refer GBV survivors to Panzi Hospital. The South Kivu Province, home to 4.614 million people, has been an epicentre of armed conflict and political instability. ${ }^{216}$ Since its inception in 1999, Panzi Hospital, an internationally recognised centre for the treatment of rape survivors, has treated more than 85864 girls and women with gynaecological injuries, more than 48000 of whom are survivors of sexual violence. ${ }^{17}$ Panzi Hospital provides comprehensive GBV care including post-rape medical care, gynaecological surgery, psychosocial and psychiatric care, and referral to safe havens and legal programmes. As a referral facility for the entire South Kivu Province, Panzi Hospital receives GBV survivors days, weeks and even months after violence, with many careseekers arriving outside of the time window for effective emergency contraception and HIV post-exposure prophylaxis. The 12 rural sites were selected by Panzi Hospital based on the following characteristics: (1) history of GBV referrals to Panzi Hospital, (2) accessibility by vehicle and (3) known absence of post-rape medical kits.

\section{THE PREVENTION PACK PROGRAM}

The Prevention Pack Program combines community sensitisation, provision of a pre-packaged post-rape medical kit, and remote inventory management using a cloud-based data system to address inventory challenges and assist GBV stakeholders in determining demand for post-rape care services. The Prevention Pack Program is not designed as a stand-alone approach to GBV; its aim is to ensure that essential post-rape care medications are always available. Each component is described below.

\section{Community sensitisation}

Panzi Hospital staff trained community health workers to increase community-level awareness of the importance, time sensitivity and availability of emergency contraception, HIV prophylaxis and STI treatment after sexual violence. In addition, radio journalists broadcast public service announcements with similar messaging that were recorded by programme staff.

\section{The Prevention Pack}

We designed the Prevention Pack (figure 1), a pre-packaged post-rape medical kit. The following medications were included in the carton: (1) emtricitabine 200 $\mathrm{mg}$ +tenofovir disoproxil fumarate $300 \mathrm{mg}$ to prevent HIV infection, 30 tablets, to be taken orally once daily for 30 days; (2) azithromycin to treat STIs, $1 \mathrm{~g}$ tablet, one-time

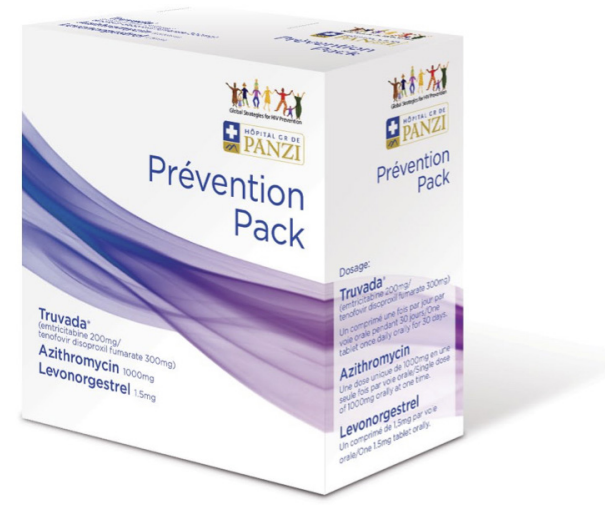

Figure 1 Prevention Pack. 
oral dose; and (3) levonorgestrel to prevent pregnancy, a single package of two $0.75 \mathrm{mg}$ tablets for one-time oral dosing. The emtricitabine/tenofovir regimen is an accepted antiretroviral regimen within the WHO guidelines and was selected for its tolerability. ${ }^{18}$ Azithromycin was selected as a single-dose first-line prophylactic agent against Chlamydia trachomatis; while no longer recommended as a first-line treatment, azithromycin is generally active against Neisseria gonorrhoeae. ${ }^{19}$ The medications were pre-packaged in a carton to eliminate the need for front-line providers to assemble the multidrug prescription. Each carton contained a punch-through calendar card for tracking the emtricitabine/tenofovir disoproxil fumarate doses. Global Strategies designed the packaging and purchased the azithromycin and levonorgestrel. Gilead Pharmaceuticals provided 4000 treatment courses (30 days) of emtricitabine/tenofovir disoproxil fumarate. The Prevention Packs were assembled by Panzi Hospital pharmacy staff and stored in the Panzi main pharmacy.

\section{Inventory management system}

Logistimo (www.logistimo.com) is a cloud-based inventory management software that allows users to create a map of locations that can receive and dispense inventory. Logistimo also allows data managers to pre-select stock levels that trigger text message alerts to project personnel. The Logistimo platform is a general inventory software and not specific to GBV. We adapted Logistimo to track both medication inventory and the number of rape survivors received at each clinic.

\section{IMPLEMENTATION Training}

In collaboration with Panzi Hospital's GBV division, we developed a training curriculum that complemented Panzi Hospital's existing GBV model. The Panzi Model is a holistic person-centred care model that encompasses four pillars: medical, psychosocial, legal and socioeconomic. ${ }^{20}$ As the rural sites did not previously have access to post-rape medical kits, we added modules to the Panzi curriculum covering the following areas: HIV prevention, infection, diagnosis and treatment; HIV post-exposure prophylaxis, prophylactic treatment of other STIs and emergency contraception; how to safely administer antiretroviral drugs; side effects of post-rape medications; sensitivity to issues of violence, confidentiality, record keeping, drug security, the Prevention Pack and inventory management.

Training was conducted by five medical doctors, a psychologist from Panzi Hospital and Congolese Prevention Pack Program personnel. The training team used didactics and role-playing exercises to teach the curriculum. Participants were introduced to the data manager responsible for the daily inventory phone calls and a representative from each site was designated to receive the calls.
Between February 2013 and February 2017, 40 community healthcare workers, 61 nurses, 6 physicians, 3 laboratory technicians and 3 journalists from local radio stations received a 3-day comprehensive training in GBV and specific information related to the Prevention Pack Program. Ongoing refresher training, as well as training for new staff members, was provided as needed.

\section{Provision of Prevention Pack}

Clinic staff evaluated individuals who presented for post-rape care. Individuals were considered eligible for, and were offered, the Prevention Pack if the rape had occurred within the last 72 hours, the victim was at least 12 years old, was not HIV infected and did not have a history of adverse reactions to the medications in the Prevention Pack. HIV testing was offered at the time of presentation. For visibly pregnant women, women who self-reported pregnancy and men, the kit was provided, but levonorgestrel was removed. Pregnancy testing was not required before Prevention Pack administration as a single dose of levonorgestrel is considered safe during pregnancy. ${ }^{21}$ Caregivers of children younger than 12 years presenting at rural clinics were given a referral note and directed to the nearest hospital. Though not required, it was strongly recommended that the first doses of medication be taken in the clinic under direct observation by the nurse. All individuals were instructed to return for follow-up care in 1 week and at 1 month.

Individuals with HIV who presented within 72 hours were offered the individual components, azithromycin and levonorgestrel. HIV-infected individuals not reporting to be receiving antiretroviral treatment were provided with a referral note and directed to the nearest HIV clinic.

Individuals presenting more than 72 hours after rape received HIV testing, azithromycin and referral to additional services as needed. To reduce the possibility that a Prevention Pack would be opened to access any element of its contents for indications other than rape within the last 72 hours, participating sites were provided with additional doses of azithromycin and levonorgestrel.

\section{Assessment of the demand and consumption of Prevention Pack}

To assess the demand and consumption of Prevention Pack inventory, we tracked the number of eligible survivors, ineligible survivors and kit inventory using Logistimo (figure 2). The data manager entered each of the 13 sites into Logistimo along with its Global Positioning System (GPS) coordinates. These sites were configured as 'entities' that could receive and dispense inventory. Participating sites received an initial stock of between 10 and 20 kits based on the self-reported demand for post-rape care medications at each clinic at the initiation of the programme. In addition to the clinics, the Panzi Hospital main pharmacy was entered into Logistimo as the inventory origin point. The Logistimo system is 


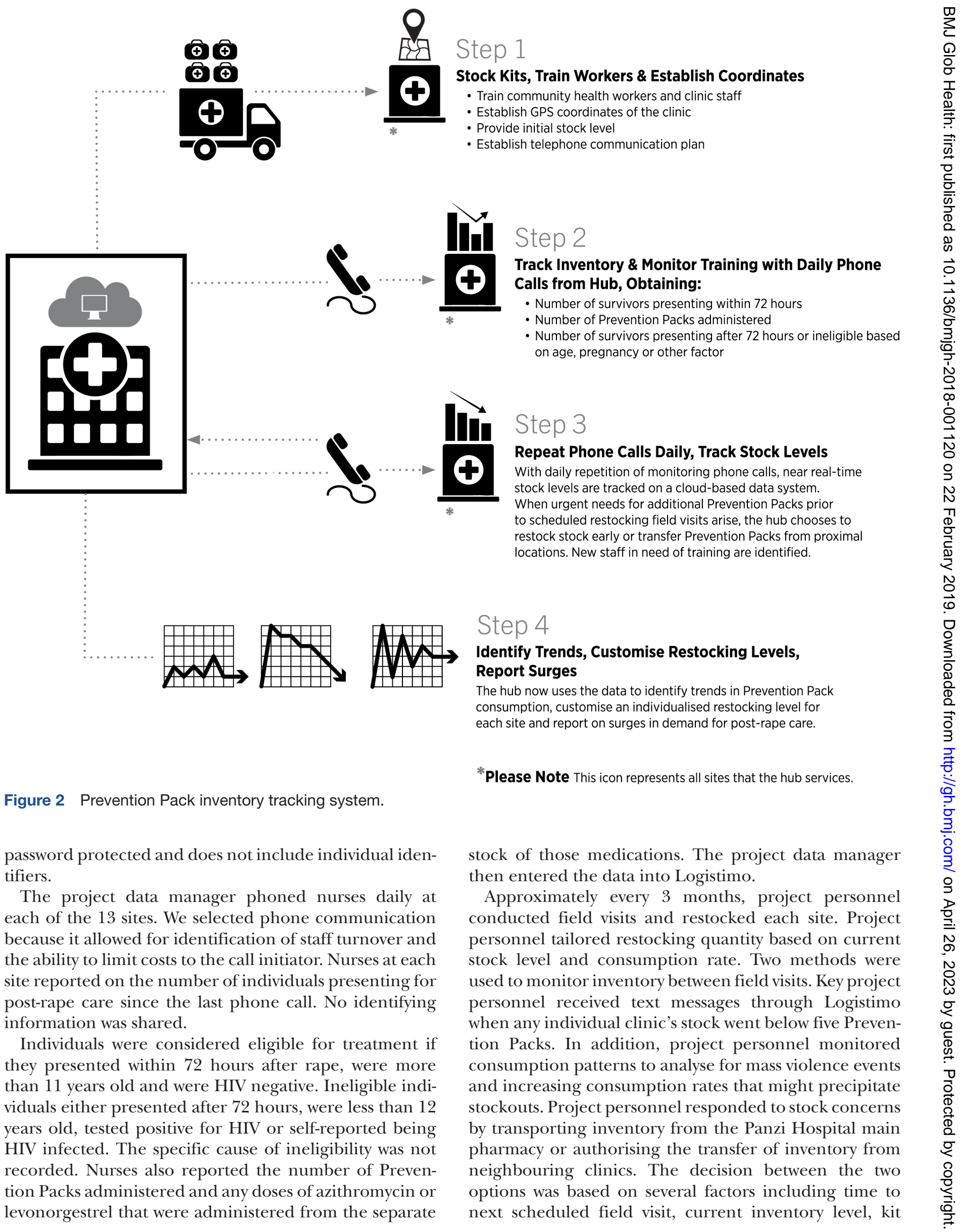


Table 1 Individuals who presented to Prevention Pack program sites between March 2013 and February 2017

Survivors presenting for care, 2013-2017

\begin{tabular}{|c|c|c|c|c|c|}
\hline Site name & Health zone & $\begin{array}{l}\text { Eligible survivors } \\
\text { and received kits }\end{array}$ & Ineligible survivors* & $\begin{array}{l}\text { Total survivors } \\
\text { presenting for care }\end{array}$ & $\begin{array}{l}\text { Survivors } \\
\text { eligible for } \\
\text { PEP }\end{array}$ \\
\hline CS Langala & Lemera & 99 & 30 & 129 & $76.7 \%$ \\
\hline CS Lubarika & Lemera & 86 & 27 & 113 & $76.1 \%$ \\
\hline CS Mulenge & Lemera & 90 & 21 & 111 & $81.1 \%$ \\
\hline CS Ndegu & Lemera & 136 & 9 & 145 & $93.8 \%$ \\
\hline CS Ndolera & Lemera & 84 & 15 & 99 & $84.8 \%$ \\
\hline CS Bushigi & Nyangezi & 73 & 7 & 80 & $91.3 \%$ \\
\hline CS Kamanyola & Nyangezi & 255 & 48 & 303 & $84.2 \%$ \\
\hline CS Kamisimbi & Nyangezi & 98 & 7 & 105 & $93.3 \%$ \\
\hline CS Munya & Nyangezi & 113 & 9 & 122 & $92.6 \%$ \\
\hline CS CEPAC Mulamba & Walungu & 75 & 13 & 88 & $85.2 \%$ \\
\hline CS Nyakakoba & Walungu & 73 & 9 & 82 & $89.0 \%$ \\
\hline Kamina Hospital & Bukavu & 29 & 8 & 37 & $78.4 \%$ \\
\hline †Panzi Hospital & Bukavu & 870 & 5922 & 6792 & $12.8 \%$ \\
\hline Total & & 2081 & 6125 & 8206 & $25.4 \%$ \\
\hline
\end{tabular}

*Ineligible survivors receive HIV testing and azithromycin for common bacterial sexually transmitted infections.

†Panzi Hospital is a referral centre that receives gender-based violence survivors from throughout the South Kivu Province.

PEP, post-exposure prophylaxis.

consumption rate, proximity to other sites, security and weather/road conditions.

\section{EVALUATION}

Between March 2013 and February 2017, a total of 8206 individuals presented for care following rape (table 1). Of the 1414 individuals who presented in the rural areas, $1211(85.6 \%)$ were eligible for and received the Prevention Pack compared with 870 of the $6792(12.8 \%)$ at Panzi Hospital. Across all sites, 6125 (74.6\%) were ineligible because they either presented after 72 hours, were less than 12 years old or were living with HIV. During the programme period, all 2081 of the eligible individuals received the Prevention Pack. Demand for post-rape care was consistent throughout the 4-year evaluation period (figure 3).

All sites from the initial group continued to participate in the Prevention Pack Program over the 4-year implementation period. Each site received eligible survivors during the programme period. The number of eligible individuals received per quarter at individual sites ranged from 1 to 126 . Though field visits were occasionally interrupted by weather or insecurity, daily phone calls continued. During the programme period, the rural sites were restocked 17 times from the Panzi Hospital main pharmacy. Though the need for restocking field visits was expected, the timing of visits and restocking quantity was determined by inventory data. In addition, 19 transfers of a total of 171 Prevention Packs between geographically proximal rural sites were recorded in Logistimo. HIV tests were available at all sites throughout the programme period. There were no reported stockouts of Prevention Pack during the 4 years.

\section{LESSONS LEARNT}

Our results demonstrate that survivors will access postrape care in remote clinics within the critical first 72 hours after rape and that stockouts of essential post-rape care medications can be eliminated. Between 2013 and 2017, we provided 2081 post-rape medical kits to survivors of sexual violence at 13 sites in the South Kivu Province of the DRC. This care was delivered continuously and without a single stockout in an unstable and remote area.

\section{KEY FINDINGS}

\section{Uptake of post-rape medical kits in rural areas}

Our results demonstrate that there is a high demand for post-rape medical kits in remote rural settings in the eastern Congo. While the WHO guidelines provide a framework for selecting medications for post-rape medical kits, there is little guidance or research regarding the optimal geographical distribution of pharmaceutical resources. Our work demonstrates the limitation of restricting post-rape care medications to urban specialty centres that require rape survivors to travel significant distances. 


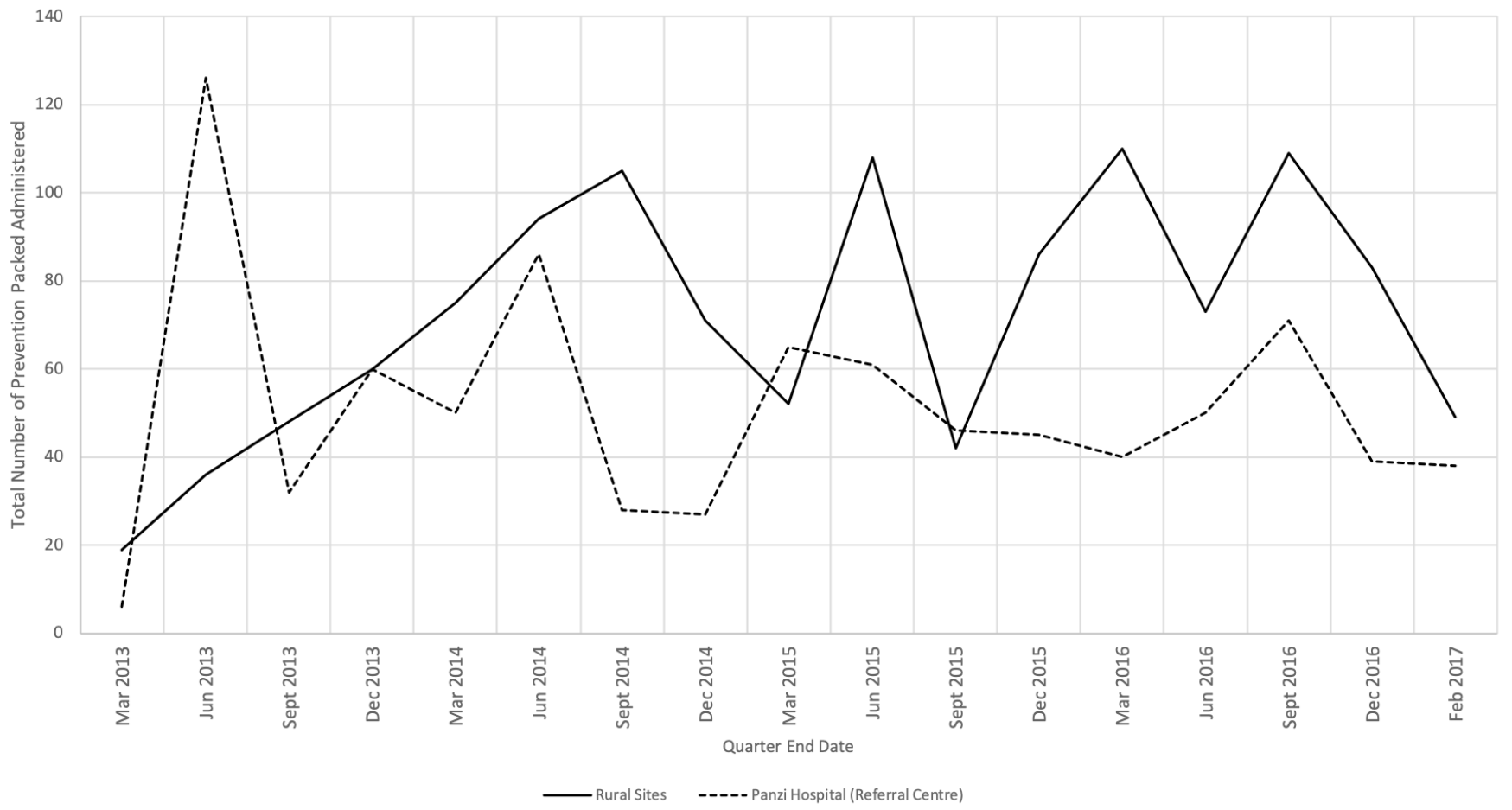

Figure 3 Prevention Pack administration referral centre vs rural sites

\section{Streamlined and simplified care}

Studies have demonstrated low percentages of rape survivors receiving HIV post-exposure prophylaxis as a result of poor provider training. ${ }^{22}$ In our study, a 3-day training, followed by intermittent refreshers and onboarding of new staff, resulted in the continuous prescription of postrape medical kits to all eligible survivors over a 4-year period in remote primary healthcare clinics. There are a number of possible explanations for this result. First, the Prevention Pack is pre-bundled. This low-cost intervention should be considered to reduce barriers to prescription and facilitate inventory tracking. Second, our study used eligibility criteria for HIV post-exposure prophylaxis consistent with the DRC and WHO guidelines that emphasise the treatment of all rape survivors who are HIV negative or unknown. ${ }^{23}{ }^{24}$ While there is agreement that HIV post-exposure prophylaxis should be offered to survivors of sexual violence, there is variation in the extent to which different guidelines emphasise treating all eligible survivors versus avoiding treatment of ineligible survivors. These subtle variations in how eligibility criteria are presented may result in variations in prescribing HIV post-exposure prophylaxis.

\section{Near real-time tracking of inventory and post-rape care demand}

The widespread stockouts of medications may be the single largest barrier to the timely delivery of emergency contraception, HIV prophylaxis and STI treatment to survivors of sexual violence. ${ }^{13}$ Our work demonstrates that stockouts can be prevented, even in remote rural areas. One possible explanation is that the Prevention Pack Program uses a push system of proactive inventory phone calls rather than a pull system that relies on rural clinics to report inventory problems. In our experience, we found that a push system facilitates implementation by removing the requirement that busy providers know they have stocked out of an infrequently used or recently introduced medical supply. Additionally, the Logistimo software allows a centralised data manager to respond to low stock levels by rapidly identifying nearby stock and facilitating transfers between clinics. Scaling this approach will require reducing implementation costs, while demonstrating the value of the system in reducing restocking visits, minimising medication waste and capturing data on demand for post-rape care.

\section{Limitations}

We acknowledge several limitations of our programme. The high number of survivors presenting at Panzi Hospital ineligible for Prevention Pack likely reflects the limited reach of our intervention: only a small subset of the clinics that refer to Panzi Hospital were incorporated into the Prevention Pack Program. Panzi Hospital is a referral centre and survivors of GBV often travel for multiple days to reach the facility. We were not able to differentiate the causes of ineligibility with current data collection mechanisms. The timing of presentation for individuals presenting after 72 hours was also not collected. Both of these data points would better 
delineate the ineligible population. While individuals who received Prevention Pack were instructed to return for follow-up, data were not collected to determine if they became pregnant, HIV infected or developed STIs. It was not feasible to collect this information. Though the medication regimen was designed to be more tolerable based on known side effect profiles, ${ }^{25}{ }^{26}$ it was not feasible to assess the tolerability and adherence to the full course of medication treatment. The true denominator of rapes in this population is unknown, as is the number of persons seeking care after sexual violence at participating sites prior to this intervention.

\section{CONCLUSION}

Effective delivery of post-rape care requires that more health centres be able to administer time-sensitive medical therapies to provide emergency contraception, prevent HIV infection and treat STIs. Barriers to providing this care include the absence of post-rape medical kits within walking distance of communities, poor training and constant stockouts. Our study demonstrates that these barriers can be reduced by simplifying care, educating communities about the availability of treatments and rigorously tracking inventory. While focusing on improving the timely delivery of post-rape medications, we acknowledge that this is a small part of a global issue and must be integrated into comprehensive GBV initiatives.

Contributors All authors contributed to the design of the programme. GK, CA, JA, $\mathrm{CM}$ and DM collected the data. JB and TR interpreted the data. JB, JA, TR and LMB analysed the data. JB, JA, TR, AJA and LMB contributed to writing the report. All authors meet the criteria for authorship. The guarantor is JB. The corresponding author had full access to all the data and had final responsibility for the decision to submit for publication.

Funding The programme was funded by the non-governmental organisation Global Strategies and the author is an employee of that organisation. Global Strategies is funded by corporate grants, private foundations and individuals. Global Strategies used seven funding sources to fund this work, one of which was a grant from Gilead Foundation. The emtricitabine/tenofovir disoproxil fumarate was provided by Gilead Sciences.

Competing interests None declared.

Patient consent for publication Not required.

Ethics approval The study was approved by Comite D'ethique, République Démocratique du Congo, ESP/CE/05113. The study was also approved by the University of California San Francisco IRB, no. 11-08229, reference no. 149347.

Provenance and peer review Not commissioned; externally peer reviewed.

Data sharing statement № additional data are available.

Open access This is an open access article distributed in accordance with the Creative Commons Attribution Non Commercial (CC BY-NC 4.0) license, which permits others to distribute, remix, adapt, build upon this work non-commercially, and license their derivative works on different terms, provided the original work is properly cited, appropriate credit is given, any changes made indicated, and the use is non-commercial. See: http://creativecommons.org/licenses/by-nc/4.0/.

\section{REFERENCES}

1. Abrahams N, Devries K, Watts C, et al. Worldwide prevalence of non-partner sexual violence: a systematic review. Lancet 2014;383:1648-54.
2. Peterman A, Palermo T, Bredenkamp C. Estimates and determinants of sexual violence against women in the Democratic Republic of Congo. Am J Public Health 2011;101:1060-7.

3. Ministère du Plan et Suivi de la Mise en œuvre de la Révolution de la Modernité (MPSMRM), Ministère de la Santé Publique (MSP) and ICF International. Democratic Republic of Congo demographic and Health survey 2013-14: key findings. Rockville, Maryland, USA: MPSMRM, MSP et ICF International, 2014: 21.

4. Alcorn T. Responding to sexual violence in armed conflict. Lancet 2014;383:2034-7.

5. Bartels SA, Scott JA, Leaning J, et al. Demographics and careseeking behaviors of sexual violence survivors in South Kivu Province, Democratic Republic of Congo. Disaster Med Public Health Prep 2012;6:393-401.

6. Garcia-Moreno C, Hegarty K, d'Oliveira A, et al. The health-systems response to violence against women. Lancet 2015;385:1567-79.

7. Johnson K, Rughita B, Scott J, et al. Association of sexual violence and human rights violations with physical and mental health in Territories of the Eastern Democratic Republic of the Congo. JAMA 2010;304:553-62.

8. UNAIDS. Democratic Republic of the Congo. Available: http://www. unaids.org/en/regionscountries/countries/democraticrepublicof thecongo

9. WHO. Responding to intimate partner violence and sexual violence against women: WHO clinical and policy guidelines. Geneva: World Health Organization, 2013.

10. Casey SE, Chynoweth SK, Cornier N, et al. Progress and gaps in reproductive health services in three humanitarian settings: mixedmethods case studies. Confl Health 2015;9(Suppl 1).

11. UNFPA. Health sector response to gender-based violence: an assessment of the Asia Pacific region. Thailand: United Nations Population Fund Asia and the Pacific Regional Office, 2010.

12. Kim JC, Martin LJ, Denny L. Rape and HIV post-exposure prophylaxis: addressing the dual epidemics in South Africa. Reprod Health Matters 2003;11:101-12.

13. Baelani I, Dünser MW. Facing medical care problems of victims of sexual violence in Goma/Eastern Democratic Republic of the Congo. Confl Health 2011;5.

14. Temmerman M. Research priorities to address violence against women and girls. Lancet 2015;385:e38-40.

15. Blanchet K, Ramesh A, Frison S, et al. Evidence on public health interventions in humanitarian crises. Lancet 2017;390:2287-96.

16. Stearns J. Causality and conflict: tracing the origins of armed groups in the eastern Congo. Peacebuilding 2014;2:157-71.

17. Panzi Foundation. Statistics. Available: http://www.panzifoundation. org/statistics

18. WHO. Consolidated guidelines on the use of antiretroviral drugs for treating and preventing HIV infection: recommendations for a public health approach. Geneva: World Health Organization, 2016.

19. Waugh MA. Open study of the safety and efficacy of a single oral dose of azithromycin for the treatment of uncomplicated gonorrhoea in men and women. J Antimicrob Chemother 1993;31(Suppl E):193-8.

20. Mukwege D, Berg M, A Holistic BM. A holistic, person-centred care model for victims of sexual violence in Democratic Republic of Congo: the Panzi Hospital one-stop centre model of care. PLoS Med 2016;13.

21. Duramed Pharmaceuticals. Levonorgestrel, 2006. Available: https://www.accessdata.fda.gov/drugsatfda_docs/label/2006/ 021045s011lbl.pdf

22. Tapesana S, Chirundu D, Shambira G, et al. Clinical care given to victims of sexual assault at Kadoma General Hospital, Zimbabwe: a secondary data analysis, 2016. BMC Infect Dis 2017;17.

23. Programme National de Lutte contre le VIH/Sida et les IST (PNLS). Module Integre de Formation des Prestataires en Paquet VIHISIDA en Republique Democratique Du Congo. Republique Democratique Du Congo: Ministère de la Santé Publique, 2017.

24. WHO. Guidelines on post-exposure prophylaxis for HIV and the use of co-trimoxazole prophylaxis for HIV-related infections among adults, adolescents and children. Recommendations for a public health approach-December 2014 supplement to the 2013 consolidated ARV guidelines. Geneva: World Health Organization, 2014.

25. Mayer KH, Mimiaga MJ, Cohen D, et al. Tenofovir DF plus lamivudine or emtricitabine for nonoccupational postexposure prophylaxis (NPEP) in a Boston community health center. J Acquir Immune Defic Syndr 2008:47:494-9.

26. WHO. Post-exposure prophylaxis to prevent HIV infection: joint WHO/ILO guidelines on post-exposure prophylaxis (PEP) to prevent HIV infection. Geneva: World Health Organization, 2007. 